\title{
SELECTING BETWEEN AUTOREGRESSIVE CONDITIONAL HETEROSKEDASTICITY MODELS: AN EMPIRICAL APPLICATION TO THE VOLATILITY OF STOCK RETURNS IN PERU*
}

\author{
SELECCION DE MODELOS DE HETEROCEDASTICIDAD \\ AUTORREGRESIVA CONDICIONAL: UNA APLICACION A LA VOLATILIDAD \\ DE LOS RETORNOS BURSATILES EN PERU
}

\section{GABRIEL RODRIGUEZ**}

Pontificia Universidad Católica del Perú

\begin{abstract}
An extensive family of univariate models of autoregressive conditional heteroskedasticity is applied to Peru's daily stock market returns for the period January 3, 1992 to March 30, 2012 with four different specifications related to the distribution of the disturbance term. This concerns capturing the asymmetries of the behavior of the volatility, as well as the presence of heavy tails in these time series. Using different statistical tests and different criteria, the results show that: (i) the FIGARCH $(1,1)$-t is the best model among all symmetric models while the FIEGARCH $(1,1)$-Sk is selected from the class of asymmetrical models. Also, the model FIAPARCH $(1,1)$-t is selected from the class of asymmetric power models; (ii) the three models capture well the behavior of the conditional volatility; (iii) however, the empirical distribution of the standardized residuals shows that the behavior of the tails is not well captured by either model; (iv) the three models suggest the presence of long memory with estimates of the fractional parameter close to the region of nonstationarity.
\end{abstract}

Keywords: Univariate autoregressive conditional heteroskedasticity models, Peruvian stock market returns, volatility, symmetries, asymmetries, normal, t-Student, skewed t-Student, GED distribution.

JEL Classification: C22, C52, C58, G12, G17.

* I appreciate the collaboration of Paul Bedón during the first part of the realization of this document when he was studying the Bachelor of Economics at the Pontificia Universidad Católica del Perú (PUCP). I also thank useful comments from Paul Castillo B. (Central Reserve Bank of Peru and PUCP). Furthermore, I appreciate the relevant comments from the Editor of the Review and one anonymous Referee. Any remaining errors are my responsibility.

** Address for Correspondence: Gabriel Rodríguez, Department of Economics, Pontificia Universidad Católica del Perú, Av. Universitaria 1801, Lima 32, Lima, Perú, Telephone: +511-626-2000 (4998), E-Mail: gabriel.rodriguez@ pucp.edu.pe. 


\section{Resumen}

Una extensiva familia de modelos univariados de heterocedasticidad autorregresiva condicional es aplicada a los retornos bursátiles diarios del Perú para el periodo del 3 de enero 1992 hasta el 30 de marzo del 2012 utilizando cuatro diferentes especificaciones para la distribución del término de perturbación. Con ello se trata de capturar asimetrías en el comportamiento de la volatilidad así como el tratamiento de colas pesadas en las series de tiempo. Utilizando diferentes estadísticos y criterios, los resultados muestran lo siguiente: (i) el modelo FIGARCH $(1,1)$-t es el mejor modelo entre todos los modelos simétricos mientras que el modelo FIEGARCH (1,1)-Sk es seleccionado entre la clase de modelos asimétricos. Asimismo, el modelo FIAPARCH $(1,1)$-t es seleccionado entre la clase de modelos de potencia asimétrica; (ii) los tres modelos capturan bien el comportamiento de la volatilidad condicional; (iii) sin embargo, la distribución empírica de los residuos estandarizados muestran que el comportamiento de las colas no es bien capturado por ninguno de los modelos; (iv) los tres modelos sugieren la presencia de larga memoria con estimados del parámetro fraccional cercanos a la región de no estacionariedad.

Palabras clave: Modelos de heterocedasticidad autorregresiva condicional, mercado bursátil peruano, volatilidad, simetrías, asimetrías, normal, t-Student, $t$-Student sesgada, distribución GED.

Clasificación JEL: C22, C52, C58, G12, G17.

\section{INTRODUCTION}

The Peruvian capitals market is undergoing expansion and constitutes an important part of the country's economic and financial development. This market channels a large proportion of financial intermediation, which is a relevant mean of financing the productive activities of both public and private companies; moreover, it plays a fundamental role in guiding the decisions of investors and companies, with a view to ensuring that resources are assigned more efficiently; see Bahi (2007). A set of stylized facts on the stock market returns and volatility is discussed in Humala and Rodríguez (2013): absence of autocorrelation in the returns, fat tails of the empirical distribution, asymmetries in the volatility linked with past negative returns, Normality in the aggregation, clustering of periods of volatility, slow decay in the autocorrelation function (ACF) for absolute returns (either power of the returns or monotonic transformations thereof) which is consistent with the presence of long memory.

On explaining the dynamic of inflation in the United Kingdom, Engle (1982) formally introduces an autoregressive conditional heteroskedasticity model (ARCH), on the basis of which a series of extensions are developed. Bollerslev (1986) presents a 
generalization of the $\mathrm{ARCH}(\mathrm{GARCH})$ process by allowing past conditional variances to be incorporated as regressors within the current conditional variance equation.

In the financial markets, the expected return of an asset, in equilibrium, depends on its risk, which can be measured by its variance. In this way, the conditional variance of an asset can influence the conditional mean. Engle et al. (1987) develop an extension of the ARCH model by allowing the conditional variance to be a determinant of the mean (ARCH-M).

Another specification of these volatility models corresponds to the integrated GARCH model (IGARCH); see also De Arce (2000), and Engle and Bollerslev (1986). Baillie et al. (1996) introduce a fractionally integrated generalized autoregressive conditional heteroskedasticity model (FIGARCH). Thus, a new kind of process is developed in which the shocks to conditional variance decay at a hyperbolic rate determined by the parameter of fractional differentiation, rendering the conditional variance more flexible.

The IGARCH and FIGARCH specifications are characterized by the non-stationarity of the volatility process. Nonetheless, this characteristic appears not to adequately fit the empirical properties of certain financial variables given the high degree of persistence implied by the integrated models. Thus, Davidson (2004) introduces the hyperbolic-GARCH (HYGARCH) model as a generalization of these models by assuming that the volatility process is stationary and long memory.

Black (1976) finds that, frequently, the changes in the returns of assets are negatively correlated with changes in their volatility. It can also be noted that negative returns predict greater volatility than positive returns of the same magnitude. This means that there is an asymmetry that is usually attributed to so-called financial leverage effects. Thus, Nelson (1991) put forward a new kind of volatility model: the exponential GARCH, or EGARCH. This type of model takes into account the leverage effects, the negative correlation between volatility and current and future returns, the inadequate restriction of the non-negativity of the variance, and the persistence of shocks.

Bollerslev and Mikkelsen (1996) propose a fractionally integrated extension of the EGARCH model of Nelson (1991), known as FIEGARCH; also see Pérez and Ruiz (2009). Meanwhile, Glosten et al. (1993) (GJR, 1993) modify the ARCH model to allow for the presence of unexpected positive and negative returns that have a different impact on the conditional variance; that is, asymmetric innovations. The GJR model allows both positive and negative innovations to produce different effects on the conditional variance and, thus, on the returns of assets (usually, the falls are longer and more sudden than the rises).

Likewise, Ding et al. (1993) put forward a generalized extension of the ARCH model, which questions the reason for assuming a linear relationship of the conditional variance based on lagged squared residuals or lagged deviation. This new model is called asymmetric power ARCH (APARCH) and allows an estimation of the long memory parameter in the volatility and the asymmetry parameter or leverage effect. Finally, Tse (1998) constructs a model by extending the APARCH model to a fractionally integrated process (FIAPARCH), incorporating the fractional process in the conditional variance. 
The empirical literature is extensive and we make no pretence at an exhaustive review here. Key references include Andersen and Bollerslev (1998), Bollerslev et al. (1992), Bollerslev et al. (1994), Engle (2001), De Arce (2004), Bollerslev (2008), and Laurent et al. (2010). However, to our knowledge, there are no studies of this type for the Peruvian case.

Other authors such as Kim and Kon (1994) compare different ARCH specifications. They find that the GJR specification (1993) is the most descriptive for individual shares, while the EGARCH model is the most apt for explaining stock market indices. Engle and $\mathrm{Ng}$ (1993) conduct a study on the event impact curve ("news"). The results of the estimations suggest that the GJR model (1993) is the best parametric model against the EGARCH, which captures much of the asymmetries of the series. Likewise, David (1997) prefers the EGARCH model.

Baillie and DeGennaro (1990) use a GARCH-M model to examine the relationship between the mean returns of a share portfolio and its conditional variance or standard deviation. Meanwhile, Koopman and Uspensky (2002) contrast ARCH-M volatility models with a stochastic volatility in mean (SVM) model. The authors present an empirical study on the intertemporal relationship between the share profitability index and their volatility for the United Kingdom, the United States, and Japan by finding a negative but weak relationship between the returns and their volatility in the current period. Giot and Laurent (2003) make use of an APARCH model based on an asymmetrical t-Student distribution to take into account the fat tails on both sides of the distribution of the returns. Moreover, Pérez and Fernández (2006) present an application of ARCH models to stock market returns of Colombia for the period 2004 to 2006. Ávalos and Hernández (1995) make use of an ARCH model to analyze stock market returns in Mexico. López-Herrera (2004) evaluates the contribution of three models from the ARCH family to model the behavior of the Mexican stock market: a symmetric GARCH model $(1,1)$ and two asymmetric $\operatorname{TARCH}(1,1)$ and EGARCH $(1,1)$ models.

In addition to stock market yields, GARCH models have been applied to study the behavior of exchange rate yields. Pozo (1992) shows that an increase in exchange rate volatility reduces commercial volume. Wang et al. (2001) establishes that the prices of many assets, including exchange rates, display periods of stability followed by strong fluctuations or interruptions. Moreover, Amigo (1997) makes use of an $\mathrm{ARCH}$ model to analyze whether they can adequately explain the volatility present in the Spanish exchange rate market for the period 1991-1993, finding evidence in favor of a GARCH(1,1) model.

On the other hand, Koutmos and Theodossiou (1994) analyze the predictability and properties of the weekly percentage change in the Greek exchange rate with respect to the most traded currencies in the country. The analysis is carried out using an EGARCH-M model along with an exponential distribution. Moreover, Gonzáles and Viñas (1996) examine the statistical properties of the first logarithmic differences of the daily exchange rates for the period 1890-1995 and two sub periods. The authors find that both ARCH and GARCH effects are located within the conditional variance to a significant degree. On the other hand, Engle et al. (1990) attempt to explain the causes of volatility clustering in the exchange rates through the use of a GARCH 
model to specify heteroskedasticity across the intra-daily market segments. Olowe (2009) investigates the volatility of the Naira/Dollar exchange rates in Nigeria using GARCH $(1,1)$, GJR-GARCH(1,1), EGARCH(1,1), $\operatorname{APARCH}(1,1), \operatorname{IGARCH}(1,1)$ and TS-GARCH(1,1) models. In addition, Mckenzie (1998) attempts to predict the volatility of the Australian exchange rate. His results suggest that the ARCH models generate a superior prediction when the squared returns of the exchange rate series are considered. Davidson (2004) finds evidence that backs this model for the exchange rates of Asian countries in the period 1994-2000, though he points to the FIGARCH model as being favored by a series of countries. It is seen that, unlike in the securities market, the shocks of appreciation and depreciation of the yen per dollar have similar effects on future volatilities (Tse, 1998); see also Conrad et al. (2011).

It is fair to say that Humala and Rodríguez (2013) represent our starting point and the beginning of a research agenda where the present document is the initial investigation with the most traditional econometric tools. It is a first attempt to explain some of the facts mentioned by Humala and Rodríguez (2013). In this paper, the models try to capture the clustering, asymmetries and heavy tails mentioned in the literature and mentioned or found in particular for the Peruvian stock market by Humala and Rodríguez (2013). However, the approach of Humala and Rodríguez (2013) is more of a statistical-descriptive type approach and there is nothing from the point of view of econometric estimation. That is why we estimate an extensive group of models, both symmetric and asymmetric and use different distributions for the error term with the objective of capturing the heavy tails already mentioned. We also include fractional models to capture the long memory feature.

Hence, in this paper, an extensive family of univariate models of autoregressive conditional heteroskedasticity is applied to Peruvian daily stock market returns for the period January 3, 1992 to March 30, 2012 (5,053 observations) with four different specifications related to the distribution of the disturbance term. This concerns capturing the asymmetries of the behavior of the volatility, as well as the presence of heavy tails in these time series. Using different statistical tests and different criteria, the results show the following: (i) the FIGARCH (1,1)-t is the best model among all symmetric models while the FIEGARCH $(1,1)-S k$ is selected from the class of asymmetrical models. Also, the model FIAPARCH $(1,1)$-t is selected from the class of asymmetric power models; (ii) the three models capture well the behavior of the conditional volatility; (iii) the model FIEGARCH $(1,1)$-Sk is the one with the best performance in terms of prediction; (iv) however, the empirical distribution of the standardized residuals shows that the behavior of the tails is not well captured by either model; (v) the three models suggest the presence of long memory with estimates of the fractional parameter close to the non-stationarity region. In fact, the models manage to capture the asymmetries, the long memory and to a lesser extent manage to capture the heavy tails. It is obvious that it is very difficult to find a model that can capture all the characteristics. But as we have already mentioned, this document is part of a larger agenda. At the same time of this investigation, we have some other progress already made in the direction of modeling volatility with particular emphasis on the characteristic of long memory.

The document is structured as follows. Section 2 briefly presents the models that are used in the empirical section. Section 3 displays and discusses the main empirical 
findings. Moreover, based on different statistical tests, the primary models for the Peruvian stock market returns are selected. Section 4 presents the main conclusions.

\section{THE MODELS}

In general, $\left\{y_{t}\right\}$ being a series of returns, an autoregressive heteroskedasticity model can be defined as

$$
\begin{gathered}
y_{t}=x_{t}^{\prime} \beta+\epsilon_{t}, \\
\epsilon_{t} \mid \Omega_{t-1} \sim f\left(0, \sigma_{t}^{2}\right), \\
\sigma_{t}^{2}=g\left[\sigma_{t-1}^{2}(\theta), \sigma_{t-2}^{2}(\theta), \ldots ; \epsilon_{t-1}(\theta), \epsilon_{t-2}(\theta), \ldots ; v_{t-1}, v_{t-2}, \ldots\right],
\end{gathered}
$$

where $x_{t}$ is a vector $k \times 1$ of endogenous and exogenous explanatory variables included in the set of information $\Omega_{t-1}, \beta$ a vector $k \times 1$ of unknown parameters, $f(\cdot)$ is a function of density, $g(\cdot)$ is a linear or non-linear functional form, and $v_{t}$ is a vector of predetermined variables included in $\Omega_{t}$. The conditional variance is a linear or non-linear function of the lagged values of $\sigma_{t}$, and $\epsilon_{t}$ and of predetermined variables $\left(v_{t-1}, v_{t-2}, \cdots\right)$ included in $\Omega_{t-1}$.

Engle (1982) defined an ARCH process as $\epsilon_{t}=z_{t} \sigma_{t}$, where $z_{t}$ is an independent and identically distributed process with $E\left(z_{t}\right)=0$ and $\operatorname{Var}\left(z_{t}\right)=1$ Moreover, it is assumed that $\epsilon_{t}$ is not serially correlated, has a mean 0 and a conditional variance equal to $\sigma_{t}^{2}$ changing over time with the equation of variance being

$$
\sigma_{t}^{2}=w+\sum_{i=1}^{q} \alpha_{i} \epsilon_{t-i}^{2}
$$

In order for the ARCH(q) process to be well defined, $\sigma_{t}^{2}, \forall t$ has to be positive. The conditions of sufficiency to assure the positivity of the variance are given by $w>0$ and $\alpha_{i} \geq 0$ for $i=1, \ldots, q$. An alternative way of describing the $\mathrm{ARCH}(\mathrm{q})$ process, according to Degiannakis and Xekalaki (2004), is given by: $\sigma_{t}^{2}=w+\alpha(L) \epsilon_{t}^{2}$, where $L$ represents the lag operator and $\alpha(L)=\alpha_{1} L+\alpha_{2} L^{2}+\ldots+\alpha_{q} L^{q}$.

In the GARCH model of Bollerslev (1986), it is found that

$$
\sigma_{t}^{2}=w+\sum_{i=1}^{q} \alpha_{i} \epsilon_{t-i}^{2}+\sum_{j=1}^{p} \beta_{j} \sigma_{t-j}^{2}
$$

where, using the lag operator $L$, the $\operatorname{GARCH}$ model $(\mathrm{p}, \mathrm{q})$ can be written as:

$$
\sigma_{t}^{2}=w+\alpha(L) \epsilon_{t}^{2}+\beta(L) \sigma_{t}^{2}
$$


which reduces the number of estimated parameters by imposing restrictions so that the conditional variance is positively defined: $w>0, \alpha_{i} \geq 0$ for $i=1, \ldots, q$ and $\beta_{i} \geq 0$ for $i=1, \ldots p$ and where $\alpha(L)=\alpha_{1} L+\alpha_{2} L^{2}+\ldots+\alpha_{q} L^{q}$ and $\beta(L)=\beta_{1} L+\beta_{2} L^{2}+\ldots+\beta_{q} L^{q}$.

The ARCH-M model of Engle et al. (1987) proposes that

$$
y_{t}=x_{t}^{\prime} \beta+\phi\left(\sigma_{t}^{2}\right)+\epsilon_{t},
$$

where $\phi\left(\sigma_{t}^{2}\right)$ represents the risk premium. The ARCH-M model is frequently used in financial time series where the expected risk depends on its return. The estimated coefficient of this risk helps to analyze the risk-return trade-off.

The EGARCH model of Nelson (1991) is formulated in terms of the logarithm of conditional variance. Following Degiannakis and Xekalaki (2004), the conditional variance of the $\operatorname{EGARCH}(p, q)$ model is represented by

$$
\log \left(\sigma_{t}^{2}\right)=w+\sum_{i=1}^{q} \pi_{i} g\left(\frac{\epsilon_{t-i}}{\sigma_{t-i}}\right)
$$

where $\pi \equiv 1$. In turn, the model incorporates the asymmetrical relationship between the squared returns and the shifts in the volatility, rendering $g\left(\epsilon_{t} / \sigma_{t}\right)$ a linear combination of $\left|\epsilon_{t} / \sigma_{t}\right|$ and $\epsilon_{t} / \sigma_{t}$ Thus, we have:

$$
g\left(\epsilon_{t} / \sigma_{t}\right)=\gamma_{1}\left(\epsilon_{t} / \sigma_{t}\right)+\gamma_{2}\left(\left|\epsilon_{t} / \sigma_{t}\right|-E\left|\epsilon_{t} / \sigma_{t}\right|\right)
$$

where $\gamma_{1}$ and $\gamma_{2}$ are constant. Let us note that $z_{t}=\epsilon_{t} / \sigma_{t}$ and $E\left(\left|\epsilon_{t} / \sigma_{t}\right|\right)=\sqrt{2 / \pi}$. The innovation of the equation $\log \left(\sigma_{t}^{2}\right)$ will be positive (negative) when the magnitude of $z_{t}$ is larger (smaller) than its expected value. As Degiannakis and Xekalaki (2004) point out, a natural parametrization is to model the conditional variance as an autoregressive moving average model $^{1}$ :

$$
\log \left(\sigma_{t}^{2}\right)=w+[1+\alpha(L)][1-\beta(L)]^{-1} g\left(z_{t-1}\right) .
$$

The GJR (1993) model specifies both the positive and negative asymmetry of the innovations through the incorporation of a dummy variable:

$$
\sigma_{t}^{2}=w+\sum_{i=1}^{q}\left(\alpha_{i} \epsilon_{t-i}^{2}\right)+\sum_{i=1}^{q}\left(\gamma_{i} S_{t-i}^{-} \epsilon_{t-i}^{2}\right)+\sum_{j=1}^{p}\left(\beta_{j} \sigma_{j-i}^{2}\right)
$$

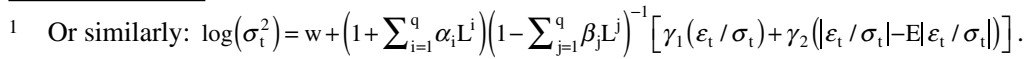


where $\gamma_{i}$ for $i=1, \ldots, q$ are parameters that have to be estimated, $S_{t}^{-}$is a dummy variable that takes the value of 1 when $\epsilon_{t-i}<0$ and takes the value of 0 if $\epsilon_{t-i}>0$. In other words, it recognizes the presence of "good" $\left(\epsilon_{t-i}>0\right)$ and "bad" $\left(\epsilon_{t-i}<0\right)$ news by assuming that the impact of $\epsilon_{t}^{2}$ on the conditional variance is different if $\epsilon_{t}$ is positive or negative.

In the APARCH model of Ding et al. (1993) it is found that

$$
\sigma_{t}^{\delta}=w+\sum_{i=1}^{q} \alpha_{i}\left(\left|\epsilon_{t-i}^{2}\right|-\gamma_{i} \epsilon_{t-i}\right)^{\delta}+\sum_{j=1}^{p}\left(\beta_{j} \sigma_{j-i}^{\delta}\right),
$$

where $\delta>0$ and $-1<\gamma_{i}<1 \forall i=1, \ldots, q$. Moreover, $w>0, \delta \geq 0$ and $\beta_{j} \geq 0 j=0, \ldots, p$. As detailed by Degiannakis and Xekalaki (2004), this model imposes a Box-Cox (1964) power transformation of the conditional standard deviation process and of the absolute asymmetric innovations. Within this expression, $\delta$ assumes the role of the Box-Cox transformation of $\sigma_{t}$ while $\gamma_{i}$ reflects the leverage effect. Moreover, this model has the peculiarity of including another seven ARCH models as special cases: (i) the ARCH model of Engle (1982) when $\delta=2, \gamma_{i}=0(i=1, \ldots, p)$ and $\beta_{j}=0(j=1, \ldots, p)$; (ii) the GARCH model of Bollerslev (1986) when $\delta=2, \gamma_{i}=0(i=1, \ldots, p)$; (iii) the GARCH model of Taylor (1986) and Schewert (1990) when $\delta=1, \gamma_{i}=0(i=1, \ldots, p)$; (iv) the model of GJR (1993) when $\delta=2$; (v) the TARCH model of Zakoian (1994) when $\delta=1$; (vi) the NARCH model of Bera and Higgins (1993) when $\gamma_{i}=0(i=1, \ldots, p)$ and $\beta_{j}=0$ $(j=1, \ldots, p)$; (vii) the log-ARCH of Geweke (1996) and Pantula (1986) when $\delta \Rightarrow 0$.

The IGARCH model seeks to estimate the conditional variance of the financial time series in the event that this is integrated, I(1). This model was put forward by Engle and Bollerslev (1986):

$$
\begin{gathered}
\sigma_{t}^{2}=w+\sum_{i=1}^{q} \alpha_{i} \epsilon_{t-i}^{2}+\sum_{j=1}^{p} \beta_{j} \sigma_{t-j}^{2}, \\
\sigma_{t}^{2}=w+\alpha(L) \epsilon_{t-i}^{2}+\beta(L) \sigma_{t-j}^{2},
\end{gathered}
$$

for $\sum_{i=1}^{q} \alpha_{i}+\sum_{j=1}^{p} \beta_{j}=1$ or $\alpha(L)+\beta(L)=1$. The IGARCH model is based on a GARCH model $(\mathrm{p}, \mathrm{q})$ whose conditional variance displays a high degree of persistence, where the polynomial $\alpha(L)+\beta(L)=1$ has $\mathrm{r}>0$ roots and $\max (\mathrm{p}, \mathrm{q})-\mathrm{r}$ roots outside the unit circle.

In the FIGARCH model of Baillie et al. (1996), the specification is

$$
\phi(L)(1-L)^{d} \epsilon_{t}^{2}=w+[1-\beta(L)] v_{t},
$$

where $\phi(L) \equiv[1-\alpha(L)-\beta(L)](1-L)^{-d}, 0<d<1$ and $v_{t}=\epsilon_{t}^{2}-\sigma_{t}^{2}$. The process $\left\{v_{t}\right\}$ is interpreted as the innovations for the conditional variance. Thus, the conditional variance of the process is defined as: 


$$
\begin{gathered}
\sigma_{t}^{2}=w[1-\beta(L)]^{-1}+\left\{1-[1-\beta(L)]^{-1} \phi(L)(1-L)^{d}\right\} \epsilon_{t}^{2} \\
=w[1-\beta(L)]^{-1}+\lambda(L) \epsilon_{t}^{2} .
\end{gathered}
$$

Bollerslev and Mikkelsen (1996) defined the FIEGARCH model as:

$$
\log \left(\sigma_{t}^{2}\right)=w+\phi(L)^{-1}(1-L)^{-d}[1+\alpha(L)] g\left(z_{t-1}\right)
$$

Similarly, Tse (1998) suggests the FIAPARCH model where the conditional variance is expressed as:

$$
\sigma_{t}^{\delta}=w+\left\{1-[1-\beta(L)]^{-1} \phi(L)(1-L)^{d}\right\}\left(\left|\epsilon_{t}\right|-\gamma \epsilon_{t}\right)^{\delta} .
$$

Davidson (2004) introduces the HYGARCH model as a generalization of the IGARCH and the FIGARCH models. The HYGARCH model is given by

$$
\sigma_{t}^{2}=w[1-\beta(L)]^{-1}+\left\{1-[1-\beta(L)]^{-1} \phi(L)\left[1+\alpha(1-L)^{d}\right]\right\} \epsilon_{t}^{2} .
$$

The HYGARCH model nests the FIGARCH model when $\alpha=1$, and the process is stationary when $\alpha<1$.

\section{EMPIRICAL RESULTS}

\section{III.1. THE DATA}

The series of stock market returns consists of 5,053 daily observations calculated using the General Index of the Lima Stock Exchange (IGBVL) for the period January 3, 1992 to March 30, 2012. Moreover, in the volatility analysis of the stock market returns, there may be a presence of "day-of-the-week" effects; that is, effects related to the days on which stock markets open (Monday) and close (Friday) that can affect market volatility; see Alberg et al. (2008). Thus, dummy variables are introduced in the regression analysis. Many studies have documented the presence of these effects on financial markets; see Cross (1973), French (1980), Alexakis and Xanthakis (1995) and Peña, (1995), among others.

Figure 1 displays the stock market returns (Top Panel). The series exhibits periods of high and low volatility (clustering), representing a clear sign of the presence of ARCH effects. The middle Panel displays the ACF of the returns while the last Panel shows the ACF of the squared returns. This Figure presents clear evidence of long memory.

The unconditional distribution of the stock market returns is shown in Figure 2 (Top Panel), and is compared with the Normal density. Its peak is higher (solid line) than the Normal density (dotted line). Moreover, it has fatter tails which can be seen 


\section{FIGURE 1}

FROM TOP TO BOTTOM: DAILY STOCK RETURNS, ACF OF DAILY STOCK RETURNS AND ACF OF DAILY STOCK SQUARED RETURNS
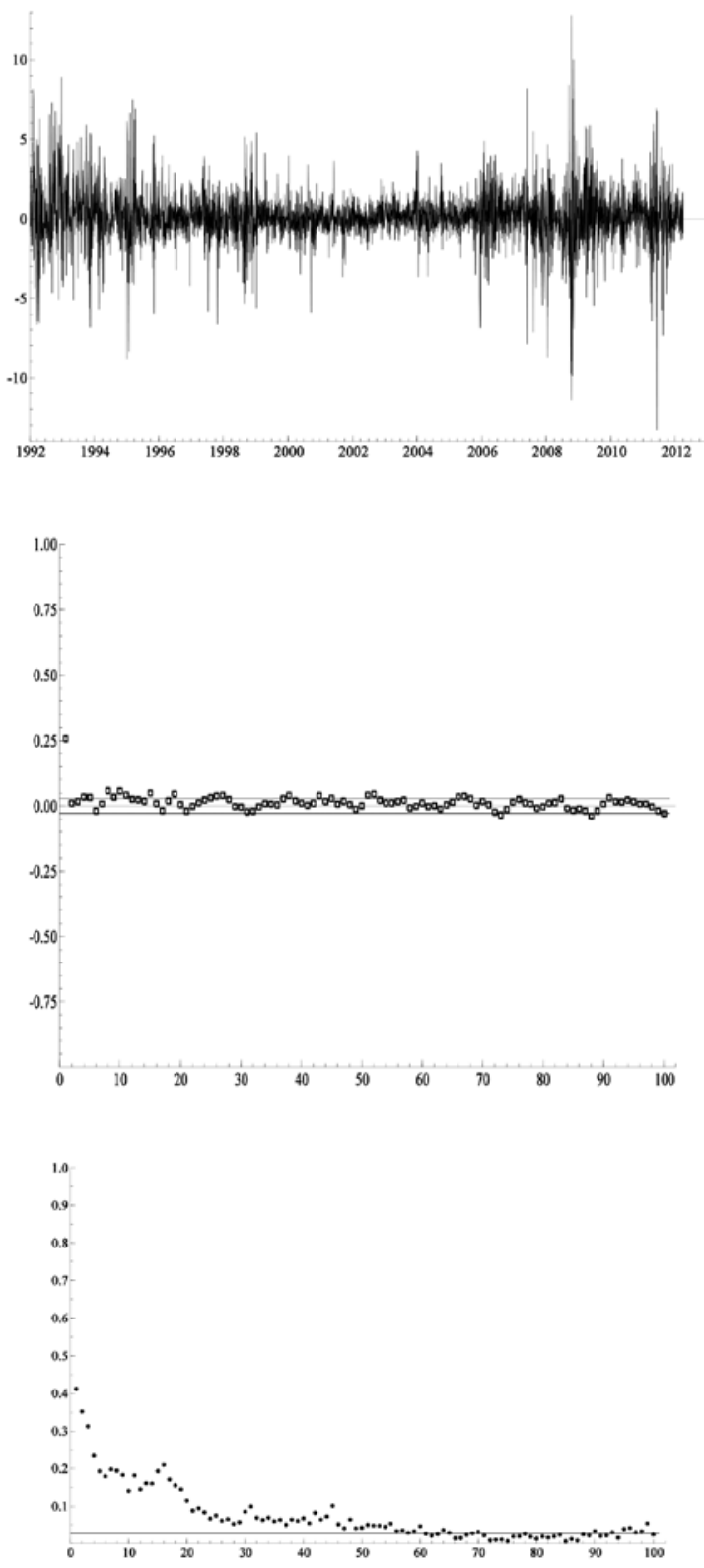


\section{FIGURE 2}

FROM TOP TO BOTTOM: DENSITY FUNCTION OF RETURNS, LEFT TAIL DENSITY OF RETURNS AND RIGTH TAIL DENSITY OF RETURNS
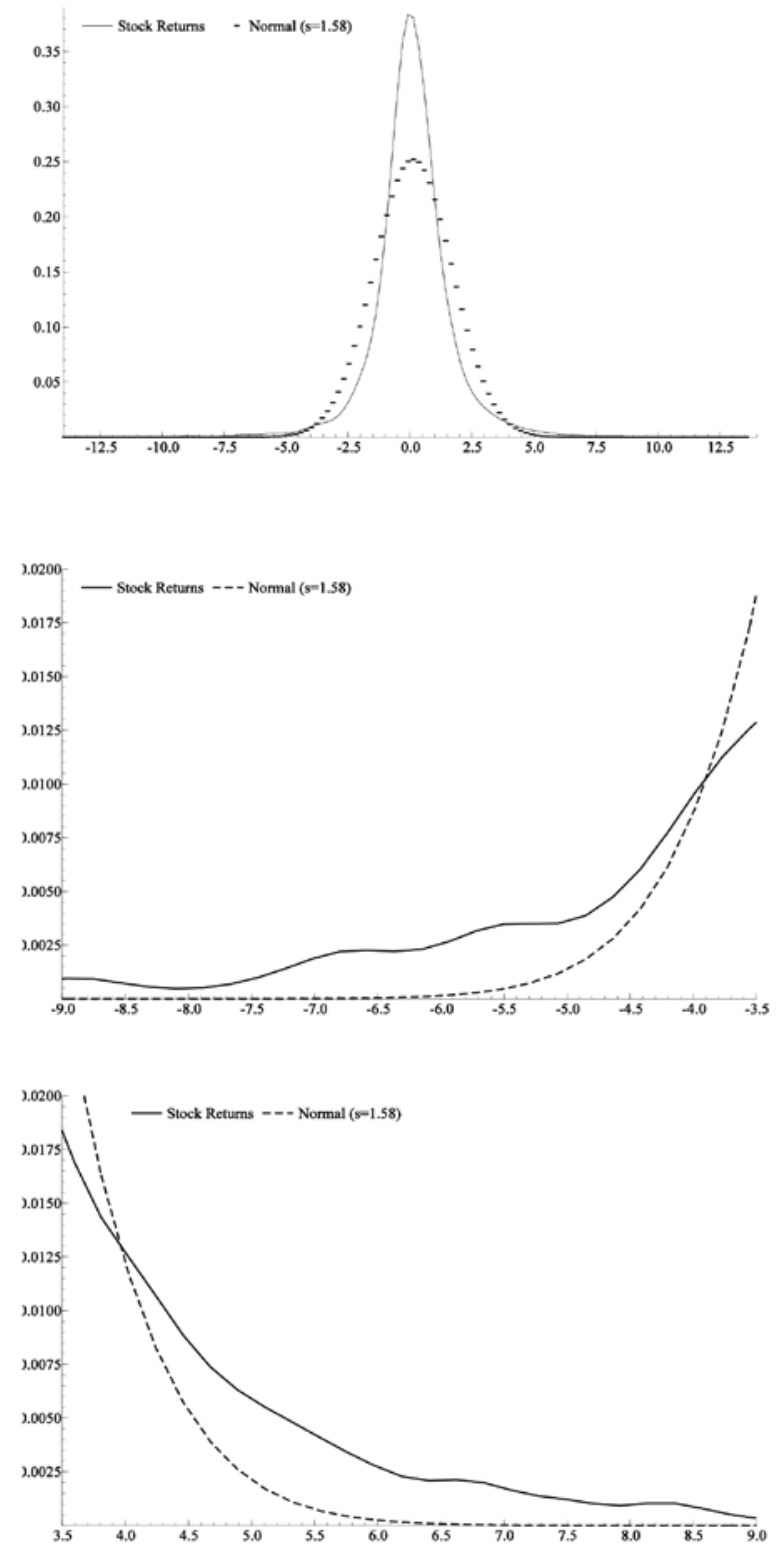
on Figure 2 (middle Panel and lower Panel). In addition, the skewness (-0.139) and the kurtosis (10.571) -located above the values of 0 and 3, respectively, for a symmetric distribution, highlight this characteristic. This is an indicator of the presence of an asymmetric distribution with heavy tails.

The estimations of the models consist of two equations: one for the mean, which is specified as $\operatorname{ARMA}(\mathrm{p}, \mathrm{q})$ models, for $p, q=0,1,2$ and another for the variance, which is specified as $\operatorname{ARCH}(1), \operatorname{GARCH}(1,1), \operatorname{EGARCH}(1,1), \operatorname{GJR}(1,1), \operatorname{APARCH}(1,1)$, $\operatorname{IGARCH}(1,1), \operatorname{FIGARCH}(1,1), \operatorname{FIEGARCH}(1,1), \operatorname{FIAPARCH}(1,1), \operatorname{HYGARCH}(1$, and ARCH(1)-M. The objective is to find, firstly, the mean equation, and secondly, the best model for volatility within the ARCH specification. All models are estimated using four different specifications relative to the distribution of the disturbance term: Normal, t-Student, Skeweed, and generalized error distribution (GED).

In order to select the best models, the following statistics are used: (i) the LM-ARCH statistic to check for the presence of ARCH effects on the residuals of the models; (ii) four information criteria: Akaike (AIC), Schwartz (BIC), Hannan-Quinn (HQ) and Shibata (SH); (iii) the diagnostic statistic of Engle and $\mathrm{Ng}$ (1993) that investigates possible specification errors in the conditional variance equation. To test for the presence of leverage effects, the Sign Bias (SB) statistic is used, which examines the impact on the conditional variance due to the positive or negative innovations not predicted by the estimated model; the Negative Sign Bias (NSB) statistic, which focuses on the impacts of the negative innovations on the conditioned variance; and the Positive Sign Bias (PSB) statistic, which estimates the effect of the positive innovations. Finally, the joint statistic (JT), which indicates the benefits of the volatility model with respect to the three statistics aforementioned. These statistics test whether the negative or positive shocks on the conditional variance depend on their size and how they affect conditional volatility; (iv) the adjusted Pearson goodness-of-fit statistic, which compares the empirical distribution of the innovations with the theoretical. In order to carry out this process, it is necessary to classify the residuals in cells according to their magnitude. For observations i.i.d., Palm and Vlaar (1997) show that the null hypothesis of a correct distribution is limited between a $\chi_{(r-1)}^{2}$ and a $\chi_{(r-k-1)}^{2}$ where $k$ is the number of estimated parameters; (v) the Residual-Based Diagnostic (RBD) statistic for detecting conditional heteroskedasticity suggested by Tse (2002); (vi) the $Q$ statistic on the standardized residuals, and the squared standardized residuals.

\section{III.2. RESULTS ${ }^{2}$}

With respect to the mean equation, different specifications were tested out, and the best was found to be an AR(1) process. Moreover, with respect to the dummy variables linked to two weekdays (Monday and Friday), in most of the estimations these variables are statistically significant. In general their signs are negative, reflecting the

2 The number of estimated models jointly to the different specifications of the distribution of the disturbance term, give rise to a large number of Tables. The complete set of these Tables is available upon request. In this paper, we only include the most important. 
fact that the returns and the volatility are, on average, lower on those days, especially on Friday ${ }^{3}$.

We start with the symmetric models. Starting with the ARCH(1) model and using the logarithm of likelihood, we find that the best performing model is between the $\mathrm{ARCH}(1)-\mathrm{t}$ and the ARCH(1)-Sk. Nonetheless, the asymmetry coefficient of the t-Sk distribution is not statistically significant, so we reject this model. Under the four criteria of information, the ARCH(1,1)-t is better than the ARCH(1)-Sk model. On the other hand, the four models reject the null hypothesis of no ARCH effects, so a specification of this type for modeling the volatility of stock market returns does not seem adequate. The SB, NSB and PSB statistics are not significant in all situations; that is, the models would be correctly incorporating the positive and negative innovations. Nonetheless, the JT is not significant only in the ARCH(1)-N, with the rest of the models giving bad results with relation to the modeling of shocks on the conditional variance. The Q statistics applied to standardized squared residuals display a rejection of the null hypothesis. Finally, the Pearson Chi-Square goodness-of-fit statistic suggests that the $\mathrm{ARCH}(1)-\mathrm{t}$ and $\mathrm{ARCH}(1)-\mathrm{Sk}$ models do not reject the null hypothesis. In conclusion, the best model in this group would be the ARCH(1)-t.

The results for the $\operatorname{GARCH}(1,1)$ family show that the asymmetry parameter of the Sk specification is not significant. Observing the four information criteria, we find that the best model is the GARCH(1,1)-t. The four models account for ARCH effects (the null hypothesis of no ARCH effects is not rejected). The RBD statistic with several lags helps us to analyze the presence of conditional heteroskedasticity in the time series, and we observe that the GARCH-t and GARCH-Sk specifications are not appropriate, while the two remaining do not present problems of this kind. Moreover, we analyze the presence of leverage effects by way of the SB, NSB, PSB and JT statistics, and it is seen that the effect of negative shocks on the conditional variance (NSB) are greater than the positive shocks (PSB) while the null hypothesis of the Joint Test (JT) is not rejected by all specifications. The statistics show that the asymmetric effect of the innovations is being captured to a large extent. In turn, the Q statistic applied to the standardized squared residuals does not reject the null hypothesis of no serial correlation at the $1 \%$ of significance in the four distributions. Moreover, the $\mathrm{P}$ statistic (with different numbers of cells) rejects the null hypothesis of a correct specification (both p-values) in the GARCH(1,1)-N and GARCH $(1,1)$ GED models, while the remaining models do not reject the hypothesis. In summary, combining all criteria used, the best model would be the GARCH(1,1)-t.

Regarding the set of asymmetric models, in the $\operatorname{EGARCH}(1,1)$ model, the parameters $\beta_{1}$ and $\theta_{1}$ and $\theta_{2}$ are significant, assuming the four distributions with the exception

3 It is important to clarify that the main objective of this document is the modeling of volatility, that is, the second equation of the different models used. The first equation, that is, the equation of the mean of the returns is not the main objective in the sense that the returns have almost not persistence. We estimated ARMA (p,q) models for $p, q=0,1,2$, however the use of an $\operatorname{AR}(1)$ model is completely sufficient. In fact, many times, estimates of the AR(1) parameter are very small and in many cases they are not significant. Given our basic interest in the volatility equation, and in order to save space given the extensive number of models estimated, we do not include more Tables and Figures. 
of the coefficient $\alpha_{1}$, which shows statistical significance only for $\operatorname{EGARCH}(1,1)$ GED and EGARCH(1,1)-Sk. Following the logarithm of likelihood, we find that the best performing model is the $\operatorname{EGARCH}(1,1)-\mathrm{Sk}$. Nonetheless, if we analyze the four information criteria, the $\mathrm{EGARCH}(1,1)$-t displays a smaller $\mathrm{BIC}$, while the EGARCH(1,1)-Sk displays a smaller AIC, SH and HQ. None of the four models show $\mathrm{ARCH}$ effects (the null hypothesis of the ARCH effects is not rejected). The RBD statistic indicates that the four specifications are appropriate. The EGARCH models adequately capture the non-symmetric effects of shocks on the conditional variance. Adding together the results of the $\mathrm{Q}$ statistic and the $\mathrm{P}$ statistic, we can conclude that the EGARCH(1,1)-Sk model is the best model in this category.

In the case of the GJR specification, the parameters $\alpha_{1}$ and $\beta_{1}$ and $\gamma_{1}$ are significant by assuming the four distributions. Analyzing the logarithm of likelihood, we find that the best performing model is the GJR $(1,1)-S k$. However, if we analyze the four information criteria, we find that the best model is the GJR(1,1)-t. The four models do not find evidence of ARCH effects. The RBD statistic tells us that the GJR-GED specification is not appropriate, while the rest of the models have some problems with heteroskedasticity. The negative shocks on the conditional variance (NSB) are slightly greater than the positive shocks (PSB). Adding together the results with the Q statistic and the P statistic, we find that the best model for this specification is the $\operatorname{GJR}(1,1)-\mathrm{Sk}$.

In the case of the APARCH $(1,1)$ specification, the parameters $\alpha_{1}, \beta_{1}$ and $\gamma_{1}$ and $\delta$ are significant by assuming the four distributions, and a high degree of persistence in variance is observed. As is the case with many models, the asymmetry coefficient of the APARCH(1,1)-Sk is insignificant and small, and as such this model cannot be representative. Following the logarithm of likelihood, we find that the best performing model is the APARCH(1,1)-Sk. If we analyze the four information criteria, the APARCH(1,1)-t is better than the APARCH(1,1)-Sk in the BIC and the HQ, while in the AIC and SH they are indifferent. The four models show evidence of an absence of ARCH effects. The null hypothesis of the RBD statistic is not rejected in all cases, so the specifications are adequate. The negative shocks on the conditional variance are more significant or greater than the positive shocks. In turn, the Q statistic on the standardized squared residuals show similar results to the other models. Finally, the P statistic establishes that the APARCH(1,1)-Sk model does not reject the null hypothesis. The results allow the APARCH(1,1)-t model to be selected.

The estimation of the $\operatorname{IGARCH}(1,1)$ models show that the parameters $\alpha_{1}$ and $\beta_{1}$ are significant by assuming the four distributions. Following the logarithm of likelihood, we find that the best performing model is the IGARCH(1)-Sk. Under the four information criteria, the $\operatorname{IGARCH}(1,1)$-t is the best, being indistinct from the $\mathrm{AIC}$ and the SH criteria. The four models have problems with respect to the ARCH effects remaining in the residuals. The RBD statistic establishes a correct specification for all models, above all in the $\operatorname{RBD}(2)$. There appears to be good modeling of the asymmetry of innovations. The Q statistic shows no evidence of autocorrelation in the residuals of the four models (at 1.0\%). The P statistic allows the IGARCH(1,1)-N and the IGARCH(1,1)-GED models to be discarded. In consequence, we may select the IGARCH(1,1)-t model. 
The evidence of long memory between the stylized facts of the stock market returns suggests the estimation of fractional models. The estimation of the $\operatorname{FIGARCH}(1,1)$ models suggests that the parameters $\alpha_{1}$ and $\beta_{1}$ are insignificant by assuming the four distributions. Observing the logarithm of likelihood, we find that the best model is the FIGARCH(1,1)-Sk, but the parameter of asymmetry is insignificant. The four information criteria, however, suggest evidence in favor of the FIGARCH(1,1)-t model. The four models show an absence of ARCH effects in the residuals, while the RBD statistic suggests that the four specifications are appropriate. The statistics based on the sign suggest that models of this kind capture well the behavior of the shocks on the conditional variance. The residuals do not show signs of autocorrelation in accordance with the Q statistic. The P statistic allows us to discard the FIGARCH(1,1)-N and FIGARCH(1,1)-GED models. The conclusion is the selection of the FIGARCH(1,1)-t model.

With respect to the estimations of the FIEGARCH( $(1,1)$ models, the parameters $\alpha_{1}, \beta_{1}$ are insignificant, unlike the $\theta_{1}$ and $\theta_{2}$ by assuming the four distributions. Following the logarithm of likelihood, we find that the best performing model is the FIEGARCH(1,1)-Sk. At the level of the four information criteria, the FIEGARCH(1,1)-Sk model continues to exceed the FIEGARCH(1,1)-t. Moreover, three of the four models do not reject the null hypothesis of the ARCH effects, with the FIEGARCH(1,1)-t displaying problems. The RBD statistic does not reject the null hypothesis of a correct specification in each model, so problems of heteroskedasticity would not be of concern. The statistics based on the signs suggest that the FIEGARCH(1,1)-Sk model is correctly incorporating the positive and negative innovations at a distance from the model. The best model in the group would be the FIEGARCH(1,1)-Sk.

As regards the estimations of the FIAPARCH $(1,1)$ models, the parameters $\alpha_{1}$ and $\beta_{1}$ are insignificant, and the opposite occurs with the parameters $\gamma_{1}$ and $\delta$. The logarithm of likelihood shows that the best-performing model is the FIAPARCH(1,1)-Sk, but the four information criteria establishes that the best model is the FIAPARCH(1,1)-t. Both models are seen to be superior to the other two. The four models does not reject the null hypothesis of no ARCH effects. The RBD statistic suggests that the four specifications are correct. The asymmetric effect of the innovations is relatively well captured by the four specifications. There is no evidence of autocorrelation in the residuals, while the $\mathrm{P}$ statistic rejects the null hypothesis of a correct specification (both p-values) in the FIAPARCH(1,1)-N and FIAPARCH $(1,1)-\mathrm{GED}$ models. The best model would be the FIAPARCH(1,1)-t.

In the case of the HYGARCH(1,1) estimations, the parameters $\alpha_{1}, \beta_{1}$ and $\alpha$ are not significant by assuming their four distributions. According to the logarithm of likelihood, we find that the best performing model is the HYGARCH(1,1)-Sk. Nonetheless, if we analyze the four information criteria we find that the best model is the HYGARCH(1,1)-t. The four models provide evidence for the absence of ARCH effects. The RBD statistic indicates that the specification is appropriate, and suggests that the leverage effects are adequately captured. There is no evidence of autocorrelation in the residuals according to the Q statistic. Moreover, the P statistic does not reject the null hypothesis of a correct specification (both p-values) in the HYGARCH(1,1)-t and HYGARCH(1,1)-Sk models. In this case, the HYGARCH(1,1)-t model is selected. 
Finally, estimations of the ARCH(1)-M models are performed, where the parameters are significant by assuming the four distributions. As with many previous models, the asymmetry coefficient of the ARCH(1)-M-Sk is insignificant and small, and so this model is not representative. Following the logarithm of likelihood, we find that the best performing models are both the ARCH(1)-M-t and the ARCH(1)-M-Sk, which have the lowest values. However, if we analyze the four information criteria, the $\mathrm{ARCH}(1)-$ $\mathrm{M}-\mathrm{t}$ is better than the ARCH(1)-M-Sk. The four models provide evidence of ARCH effects in the residuals. The positive shocks on the conditional variance are greater than the negative shocks. The Q statistic shows clear evidence of autocorrelation in the residuals estimated by the four models. They suggest a better performance of the $\mathrm{ARCH}(1)-\mathrm{M}-\mathrm{Sk}$ and $\mathrm{ARCH}(1)-\mathrm{M}-\mathrm{t}$ models. According to the criteria utilized, the model selected is $\mathrm{ARCH}(1)-\mathrm{M}$-t. It is important to mention that though we selected this model as a representative of the $\mathrm{ARCH}(1)-\mathrm{M}$ family, the different statistics suggest a poor performance of this type of models. This is unsurprising, given that it concerns simpler ARCH models, only that the mean is modeled by including volatility.

\section{III.2.1. SELECTION OF MODELS}

Given that the dependent variable changes in the different estimated models, the selection criteria of the models is applied in three different groups ${ }^{4}$. The first group, whose dependent variable is $\sigma_{t}^{2}$, is comprised of ARCH, GARCH, GJR, IGARCH, FIGARCH, HYGARCH and ARCH-M models. The second group, whose dependent variable is the $\log \left(\sigma_{t}^{2}\right)$, is comprised of EGARCH and FIEGARCH models, while the last group, whose dependent variable is $\sigma_{t}^{\delta}$, will be comprised of APARCH and FIAPARCH models.

Following the maximum likelihood criterion, the best model from the first group is the FIGARCH(1,1)-t. The best model in the second group is the FIEGARCH(1,1)-Sk, while in the last group the FIAPARCH(1,1)-t would be the representative. Moreover, analyzing the information criteria, they support the previous findings. It is important to note that all models selected belong to the group of fractional integration; that is, we have evidence of a long-memory process in the volatility.

Within the first group, the models that do not reject the null hypothesis of no ARCH effects are GARCH(1,1)-t, GJR(1,1)-t, IGARCH(1,1)-t, FIGARCH(1,1)-t and HYGARCH(1,1)-t. In this sense, according to this criteria, the $\mathrm{ARCH}(1)$-t and ARCH-M(1)-t models are discarded. Both the second and the third group provide evidence of the absence of ARCH effects in the residuals when the FIEGARCH(1,1)Sk, APARCH(1,1)-t and FIAPARCH(1,1)-t models are used.

4 In order to be rigorous in the selection of the best models, we have selected the best model within each of the classes of models mentioned. Since the dependent variable is different in the three categories, it is not correct to choose a single model for the three categories. All the statistics and criteria used are valid within each category of models according to the respective dependent variable. Even an exercise of forecasts does not allow a solution because the forecasted variables are different. Furthermore, a forecasting exercise is not considered because is beyond the scope of the paper. 
Utilizing the RBD statistic, it is observed that only the FIGARCH(1,1)-t, HYGARCH(1,1)-t and IGARCH(1,1)-t models appear to correct the problem of conditional heteroskedasticity in the estimated residuals. On the other hand, the SB, NSB, PSB and JT statistic show the presence of leverage effects, which is equivalent to stating that these models largely capture the asymmetric effects of positive and negative innovations in the variance of stock market returns. With respect to the $\mathrm{P}$ statistic, this reveals that the empirical distribution of the innovations is adjusted to the theoretical distribution in all the models in the three groups analyzed.

Based on the above-mentioned, we find that the best three models are the FIGARCH(1,1)-t, FIEGARCH(1,1)-Sk and FIAPARCH(1,1)-t, in each of the three groups analyzed, respectively. Figure 3 shows some interesting aspects. The conditional variance obtained from the three models show very similar behavior compared to the squared residuals which is a good indicator of adjustment of each of the models. On the other hand, the empirical density of the standardized residuals compared to underlying distribution used in the estimates (t-Student, Student-t and Skewed Student-t, respectively) still shows significant differences. The qq-plot confirms this: the behavior of the tails of the distribution of stock returns is not well captured by either model. Other ongoing research is looking to capture this aspect.

It is important to emphasize the long-memory aspect in the time series analyzed. The three models allow an estimate of the fractional parameter $\hat{d}=0.467,0.495,0.467$, respectively. The three estimations are close to the frontier of the stationarity $(0.5)$, and the three values indicate strong evidence of long memory. This result can be interpreted as strong evidence in favor of fractionally integrated models. Nonetheless, as the literature has pointed out, this behavior may be contaminated by the presence of sporadic or random level shifts; see Diebold and Inoue (2001), Mikosch and Stărică (2004a, 2004b), among others. From the standpoint of the application of statistics, see Perron and Qu (2010) and Qu (2011). From the standpoint of modeling, see Lu and Perron (2010), Li et al. (2016), and Xu and Perron (2014). Recent applications and research underway for the Peruvian and Latin American cases include Ojeda-Cunya and Rodríguez (2016), Rodríguez and Tramontana-Tocto (2015), Rodríguez (2016), Herrera and Rodríguez (2016), and Pardo and Rodríguez (2014). In the mentioned research, the results conclude that the volatility does not present long memory. Instead, the volatility is composed by a short memory component plus a random level shifts component.

\section{CONCLUSIONS}

It is fair to say that Humala and Rodríguez (2013) represent our starting point and the beginning of a research agenda where the present document is the initial investigation with the most traditional econometric tools. It is a first attempt to explain some of the facts mentioned by Humala and Rodríguez (2013). In this paper, the models try to capture the clustering, asymmetries and heavy tails mentioned in the literature and mentioned or found in particular for the Peruvian stock market by Humala and Rodríguez (2013). However, the approach of Humala and Rodríguez 


\section{FIGURE 3}

FROM TOP TO BOTTOM: RESULTS OF FIGARCH(1,1)-T, FIEGARCH(1,1)-SK, FIAPARCH(1,1)-T. IN EACH PANEL (FROM LEFT TO RIGTH): STOCK RETURNS, SQUARED RESIDUALS, STANDARIZED RESIDUALS, CONDITIONAL VARIANCE, KERNEL OF STANDARIZED RESIDUALS VS DENSITY FUNCTION (T OR SK), QQ-PLOT
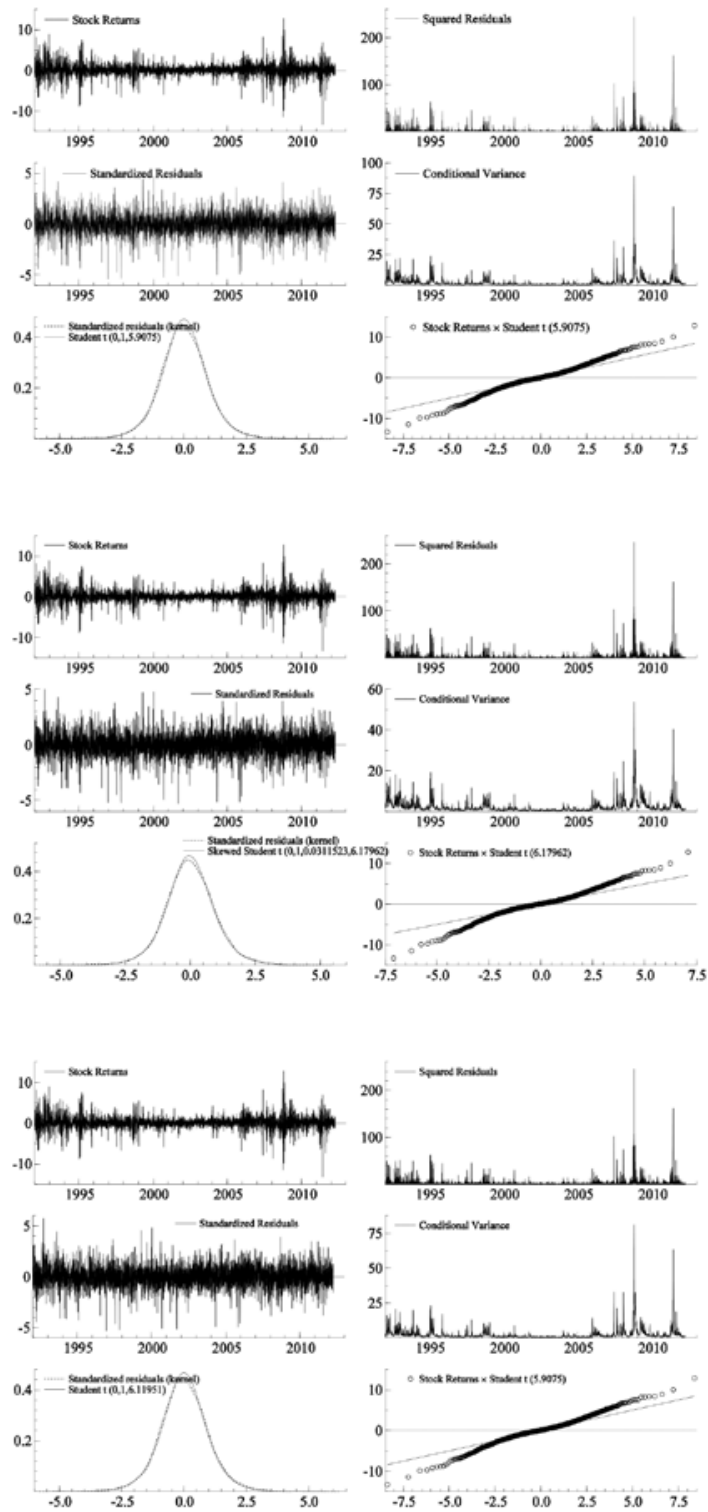
(2013) is more of a statistical-descriptive type approach and there is nothing from the point of view of econometric estimation. That is why we estimate an extensive group of models, both symmetric and asymmetric and use different distributions for the error term with the objective of capturing the heavy tails already mentioned. We also include fractional models to capture the long memory feature.

Hence, an extensive family of univariate models of autoregressive conditional heteroskedasticity is applied to the Peruvian daily stock market returns for the period January 3, 1992 to March 30, 2012 (5053 observations) with four different specifications related to the distribution of the disturbance term. This concerns capturing the asymmetries of the behavior of the volatility, as well as the presence of heavy tails in these time series. Different criteria and statistics are utilized for the process of selecting the best models. Given the different nature of the dependent variable, the models have been selected separately. Finally, the selected models are the FIGARCH(1,1)-t, the FIEGARCH(1,1)-Sk, and the FIAPARCH(1,1)-t in each of the groups divided according to the structure of the dependent variable. The selection is interesting as it reflects the following aspects: (i) it is a model that captures the asymmetries and thus the leverage effects; (ii) it is a fractionally integrated model, which allows the evidence of long memory to be captured in the volatility of stock market returns; (iii) the distribution of the disturbance term is skewed, which allows us to approximate the behavior of the structure of the disturbance term.

In fact, the models manage to capture the asymmetries, the long memory and to a lesser extent manage to capture the heavy tails. It is obvious that it is very difficult to find a model that can capture all the characteristics. But as we have already mentioned, this document is part of a larger agenda. At the same time of this investigation, we have some other progress already made in the direction of modeling volatility with particular emphasis on the characteristic of long memory. In fact, it is important to emphasize the long-memory aspect unanimously fond in the three selected models in this paper. The three models allow an estimate of the fractional parameter $\hat{d}=0.467,0.495,0.467$, respectively. The three estimations are close to the frontier of the stationarity (0.5), and the three values indicate strong evidence of long memory. This result can be interpreted as strong evidence in favor of fractionally integrated models. Nonetheless, as the literature has pointed out, this behavior may be contaminated by the presence of sporadic or rare random level shifts; see Diebold and Inoue (2001), Mikosch and Stărică (2004a, 2004b), among others. From the standpoint of the application of statistics, see Perron and Qu (2010) and Qu (2011). From the standpoint of modeling, see Lu and Perron (2010), Li et al. (2016), and Xu and Perron (2014). Recent applications and research underway for the Peruvian and Latin American cases include Ojeda-Cunya and Rodríguez (2016), Rodríguez and Tramontana-Tocto (2015), Rodríguez (2016), Herrera and Rodríguez (2016), and Pardo and Rodríguez (2014). 


\section{BIBLIOGRAPHY}

ALEXAKIS, P. and M. XANTHAKIS (1995). "Day of the week effect on the Greek stock market", Applied Financial Economics 5, pp. 43-50.

ALBERG, D., H. SHALIT and R. YOSEF (2008). "Estimating Stock Market Volatility using Asymmetric GARCH Models", Applied Financial Economics 18 (15), pp. 1201-1208.

AMIGO, L. (1997). "Determinantes del tipo de cambio: Un modelo ARCH", Annales de estudios económicos y empresariales 12 , pp. 227-250.

ANDERSEN, T.G. and T. BOLLERSLEV (1998). "ARCH and GARCH Models", Encyclopedia of Statistical Sciences 2. New York: John Wiley and Sons.

AVALOS, A. and F. HERNANDEZ (1995). "Comportamiento del tipo de cambio real y desempeño económico en México", Nueva Epoca 4 (2), pp. 239-263.

BAHI, C.A. (2007). "Modelos de medición de la volatilidad en los mercados de valores: Aplicación al mercado bursátil Argentino," Working Paper, Universidad Nacional de Cuyo- Facultad de Ciencias Económicas.

BAILLIE, R.T., T. BOLLERSLEV and H.O. MIKKELSEN (1996). "Fractionally Integrated Generalized Autoregressive Conditional Heteroskedasticity", Journal of Econometrics 74, pp. 3-30.

BAILLIE, R.T. and R. DEGENNARO (1990). "Stock Returns and Volatility", The Journal of Financial and Quantitative Analysis 25 (2), pp. 203-214.

BERA, A.K. and M.L. HIGGINS (19932). "ARCH Models: Properties, Estimation and Testing", Journal of Economic Surveys 7, pp. 305-366.

BLACK, F. (1976). "Studies of Stock Price Volatility Changes", Proceedings of the 1976 Meetings of The American Statistical Association, Business and Economics Section, pp. 177-181.

BOLLERSLEV, T. (1986). "General Autoregressive Conditional Heteroskedasticity", Journal of Econometrics 31, pp. 307-327.

BOLLERSLEV, T. (2008). "Glossary to ARCH (GARCH)", School of Economics and ManagementUniversity of Aarhus. CREATES Research Paper 2008-49.

BOLLERSLEV, T., R.Y. CHOU and K.F. Kroner (1992). "ARCH Modeling in Finance: A Selective Review of the Theory and Empirical Evidence", Journal of Econometrics 52, pp. 5-59.

BOLLERSLEV, T., R.F. ENGLE and D.B. NELSON (1994). "ARCH Models", Handbook of Econometrics 4, pp. 2959-3038. Amsterdam: North-Holland.

BOLLERSLEV, T. and H.O. MIKKELSEN (1996). "Modeling and Pricing Long-Memory in Stock Market Volatility", Journal of Econometrics 73, pp. 151-184.

BOX, G.E.P. and D.R. COX (1964). "An analysis of transformations", Journal of the Royal Statistical Society, Series B 26 (2), pp. 211-252.

CONRAD, C., M. KARANASOS and N. ZENG (2011). "Multivariate Fractionally Integrated APARCH Modeling of Stock Market Volatility: A Multi-Country Study", Journal of Empirical Finance 18 (1), pp. 147-159.

CROSS, F. (1973). "The behavior of stock price on Fridays and Mondays", Financial Analysts Journal 29 , pp. 67-69.

DAVID, A. (1997). "Fluctuating Confidence in Stock Markets: Implications for Returns and Volatility", The Journal of Financial and Quantitative Analysis 32 (4), pp. 427-462.

DAVIDSON, J. (2004). "Moment and Memory Properties of Linear Conditional Heteroskedasticity Models, and a New Model", Journal of Business and Economic Statistics 22, pp. 16-29.

DE ARCE, R. (2000). "Modelización ARCH. Estimación de la volatilidad del IBEX-35", Tesis doctoralUniversidad Autónoma de Madrid. Publicada en la web.

DE ARCE, R. (2004). "20 años de modelos ARCH: una visión en conjunto de las distintas variantes de la familia", Estudios de Economía Aplicada 22 (1), pp. 1-27.

DEGIANNAKIS, S. and E. XEKALAKI (2004). "Autoregressive Conditional Hetscedasticity (ARCH) Models: A Review", Quality Technology and Quantitative Management 1, pp. 271-324.

DIEBOLD, F. and A. INOUE (2001). "Long memory and regime switching", Journal of Econometrics 105, pp. 131-159.

DING, Z., C.W. GRANGER and R.F. ENGLE (1993). “A Long Memory Property of Stock Market Returns and a New Model," Journal of Empirical Finance 1, 83-106. 
ENGLE, R.F. (1982). "Autoregressive Conditional Heteroskedasticity with Estimates of the Variance of U.K. Inflation", Econometrica 55 (4), pp. 324-356.

ENGLE, R.F. (2001). "GARCH 101: The Use of ARCH/GARCH Models in Applied Econometrics", Journal of Economic Perspectives 15, pp. 157-168.

ENGLE, R.F. and T. BOLLERSLEV (1986). "Modeling the Persistence of Conditional Variances", Econometric Reviews 5, pp. 1-50.

ENGLE, R.F., T. ITO and W.L. LIN (1990). "Meteor Showers or Heat Waves? Heteroskedastic Intra-Daily Volatility in the Foreign Exchange Market", Econometrica 58, pp. 525-542.

ENGLE, R.F., D.M. LILIEN and R.P. ROBINS (1987). "Estimating Time Varying Risk Premia in the Term Structure: The ARCH-M Model", Econometrica 55, pp. 391-407.

ENGLE, R.F. and V.K. NG (1993). "Measuring and Testing the Impact of News on Volatility", The Journal of Finance 48 (5), pp. 1749-1778.

FRENCH, K. (1980). "Stock returns and the weekend effect", Journal of Financial Economics 8, pp. 55-69.

GEWEKE, J. (1986). "Modeling the Persistence of Conditional Variances: A Comment", Econometric Reviews 5, pp. 57-61.

GIOT, P. and S. LAURENT (2003). "Value-at-Risk for Long and Short Trading Positions", Journal of Applied Econometrics 18 (6), pp. 641-664.

GLOSTEN, L., R. JAGANNATHAN and D. RUNKLE (1993). "On the Relation Between the Expected Value and the Volatility of the Nominal Excess Return on Stocks", Journal of Finance 48, pp. 1779-1801.

GONZALES, A. and B. VIÑAS (1996). "Estimación de la volatilidad condicional en el mercado de divisas con modelos de la familia GARCH", Investigaciones Europeas de Dirección y Economía de la Empresa 2 (3), pp. 43-59.

HERRERA-ARAMBURU, A. and G. RODRIGUEZ (2016). "Volatility of Stock Market and Exchange Rate Returns in Peru: Long Memory or Short Memory with Level Shifts?", International Journal of Monetary Economics and Finance 9 (1), pp. 45-66. It appears as Working Paper 393 of the Department of Economics, Pontificia Universidad Católica del Perú.

HUMALA, A. and G. RODRIGUEZ (2013). "Some Stylized Facts of Returns in the Stock and Foreign Exchange Markets in Peru", Studies in Economics and Finance 30 (2), pp. 139-158.

KIM, D. and S.J. KON (1994). "Alternative Models for the Conditional Heteroscedasticity of Stock Returns", The Journal of Business 67 (4), pp. 563-598.

KOOPMAN S.T. and E.H. USPENSKY (2002). "The Stochastic Volatility in Mean Model: Empirical Evidence from International Stock Markets", Journal of Applied Econometrics 17 (6), pp. 667-689.

KOUTMOS, G. and P. THEODOSSIOU (1994). "Time-Series Properties and Predictability of Greek Exchange Rates", Managerial and Decision Economics 15 (2), pp. 159-167.

LAURENT, S., K. BOUDT, J. LAHAYE, J.P. PETERS, J. ROMBOUTS and F. VIOLANTE (2010). G@ RCH 6.1, United Kingdom, Timberlake Co.

LOPEZ-HERRERA, F. (2004). "Modelado de la Volatilidad y Pronóstico del Indice de Precios y Cotizaciones de la Bolsa Mexicana de Valores", Contaduría y Administración 213, pp. 44-72.

LI, Y., P. PERRON and J. XU (2016). "Modeling Exchange Rate Volatility with Random Level Shifts", forthcoming in Applied Economics. It appears as Working Paper, Department of Economics, Boston University.

LU, Y.K. and P. PERRON (2010). "Modeling and forecasting stock return volatility using a random level shift model", Journal of Empirical Finance 17, pp. 138-156.

MCKENZIE, M.D. (1998). "The Impact of Exchange Rate Volatility on Australian Trade Flows”, Journal of International Financial Markets, Institutions and Money 8 (1), pp. 21-38.

MIKOSCH, T. and C. STĂRICĂ (2004a). "Nonstationarities in Financial Time Series, the Long-range Effect Dependence, and the IGARCH Effects", Review of Economics and Statistics 86 (1), pp. 378-390.

MIKOSCH, T. and C. STĂRICĂ (2004b). "Changes of Structure in Financial Time Series and the GARCH model”, REVSTAT-Statistical Journal 2, pp. 42-73.

NELSON, D. (1991). "Conditional Hetorskedasticity in Asset Returns: A new Approach", Econometrica 59 (2), pp. 347-370.

OJEDA-CUNYA, J. and G. RODRIGUEZ (2016). "An Application of a Random Level Shifts Model to the Volatility of Peruvian Stock and Exchange Rate Returns", Macroeconomics and Finance in Emerging Market Economies 9 (1), pp. 34-55. It appears as Working Paper 383 of the Department of Economics, Pontificia Universidad Católica del Perú. 
OLOWE, R.A. (2009). "Modelling Naira/Dollar Exchange Rate Volatility: Application of GARCH and Asymmetric Models", International Review of Business Research Papers 5 (3), pp. 377-398.

PALM, VON F.C. and P.J.G. VLAAR (1997). "Simple Diagnostic Procedures for Modeling Financial Time Series", Allg. Statisches Archiv 81, pp. 85-101.

PANTULA, S.G. (1986). "Modeling the Persistence of Conditional Variances: A Comment", Econometric Reviews 5, pp. 71-74.

PARDO-FIGUEROA, R. and G. RODRIGUEZ (2014). "Distinguishing between True and Spurious Long Memory in the Volatility of Stock Market Returns in Latin America", Working Paper 395, Department of Economics, Pontificia Universidad Católica del Perú.

PEÑA, J. (1995). "Daily seasonalities and stock market reforms in Spain", Applied Financial Economics 5, pp. 419-423.

PEREZ, O. and H. FERNANDEZ (2006). "Análisis de la volatilidad del índice general de la bolsa de valores de Colombia utilizando modelos ARCH”, Revista de Ingenierías Universidad de Medellín 5 (8), pp. 13-33.

PEREZ, A. and E. RUIZ (2009). "Modelos de memoria larga para series económicas y financieras", Documentos de trabajo de estadística y econometría. Universidad Carlos III de Madrid.

PERRON, P. and Z. QU (2010). "Long-memory and level shifts in the volatility of stock market return indices", Journal of Business and Economic Statistics 28, pp. 275-290.

POZO, S. (1992). "Conditional Exchange-Rate Volatility and the Volume of International Trade: Evidence from the Early 1900s", The Review of Economics and Statistics 74 (2), pp. 325-329.

QU, Z. (2011). "A Test Against Spurious Long Memory", Journal of Business and Economic Statistics 29, pp. 423-438.

RODRIGUEZ, G. (2016). "Modeling Latin-American Stock Markets Volatility: Varying Probabilities and Mean Reversion in a Random Level Shifts Model”, Review of Development Finance 6, pp. 26-45. It appears published as Working Paper 403, Department of Economics, Pontificia Universidad Católica del Perú.

RODRIGUEZ, G. and R. TRAMONTANA-TOCTO (2015). "An Application of a Short Memory Model with Random Level Shifts to the Volatility of Latin American Stock Market Returns", Latin American Journal of Economics 52 (2), pp. 185-211. It appears as Working Paper 385 of the Department of Economics, Pontificia Universidad Católica del Perú.

SCHWERT, G.W. (1990). "Stock Volatility and The Crash of 87", Review of Financial Studies 3, pp. 77-102.

TAYLOR, S.J. (1986). Modelling Financial Time Series. Wiley and Sons: New York, NY.

TSE, Y.K. (1998). "The Conditional Heteroskedasticity of the Yen-Dollar Exchange Rate", Journal of Applied Econometrics 193, pp. 49-55.

TSE, Y.K. (2002). "Residual-based Diagnostics for Conditional Heteroscedasticity Models", Econometrics Journal 5, pp. 358-373.

WANG, K., C. FAWSON, C. BARRETT and J. McDONALD (2001). "A Flexible Parametric GARCH Model with an Application to Exchange Rates", Journal of Applied Econometrics 16 (4), pp. 521-536.

XU, J. y P. PERRON (2014). "Forecasting Return Volatility: Level Shifts with Varying Jump Probability and Mean Reversion", International Journal of Forecasting 30, pp. 449-463.

ZAKOIAN, J.M. (1994). “Threshold Heteroskedasticity Models”, Journal of Economic Dynamics and Control 


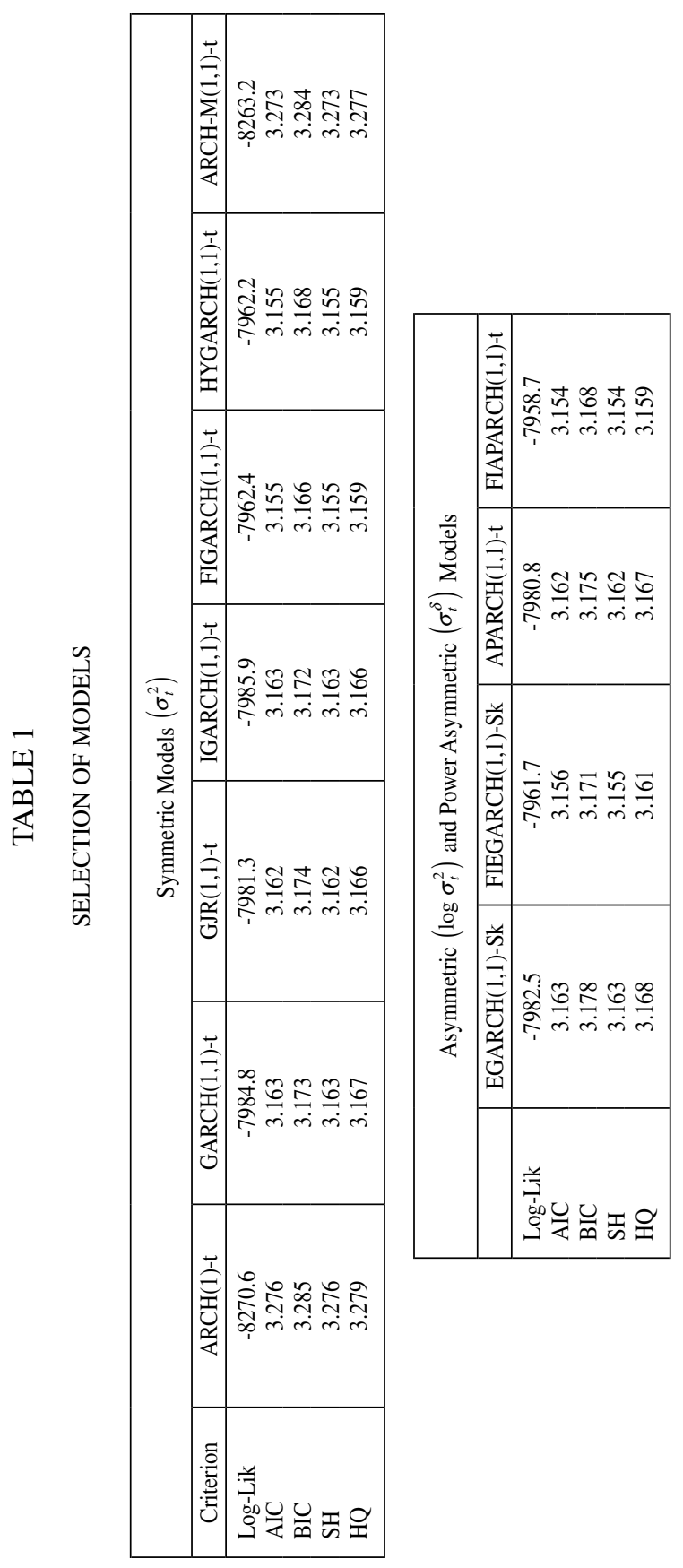




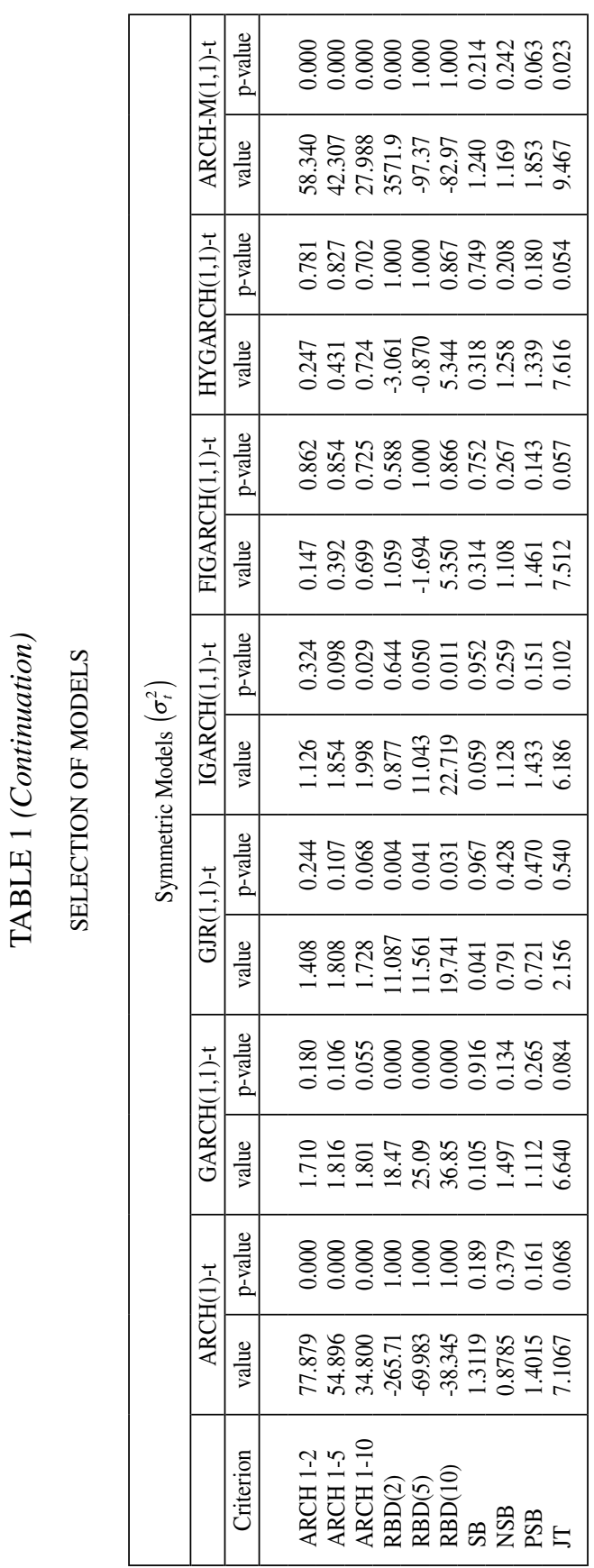

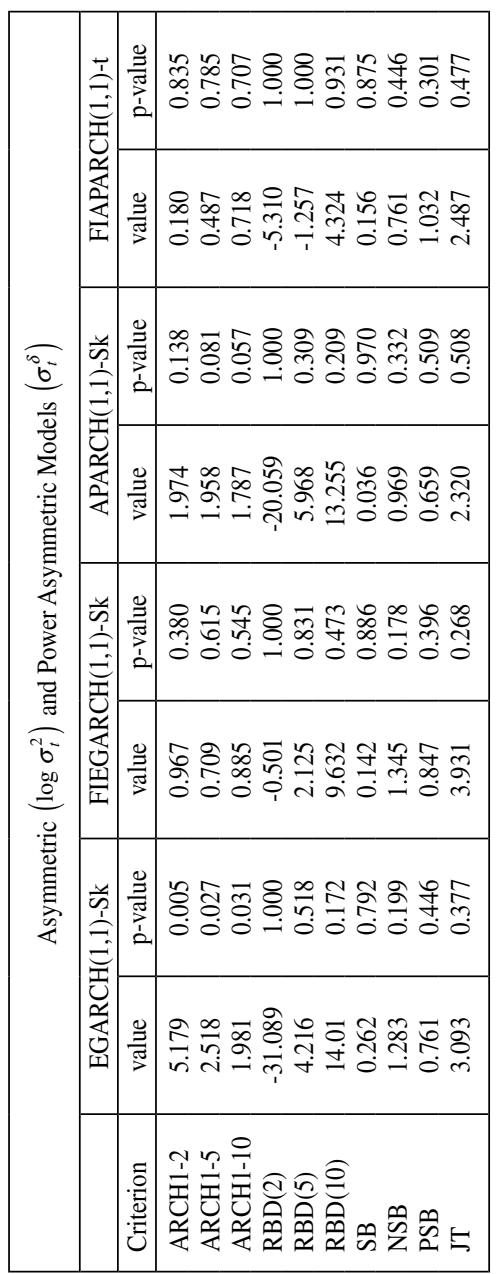




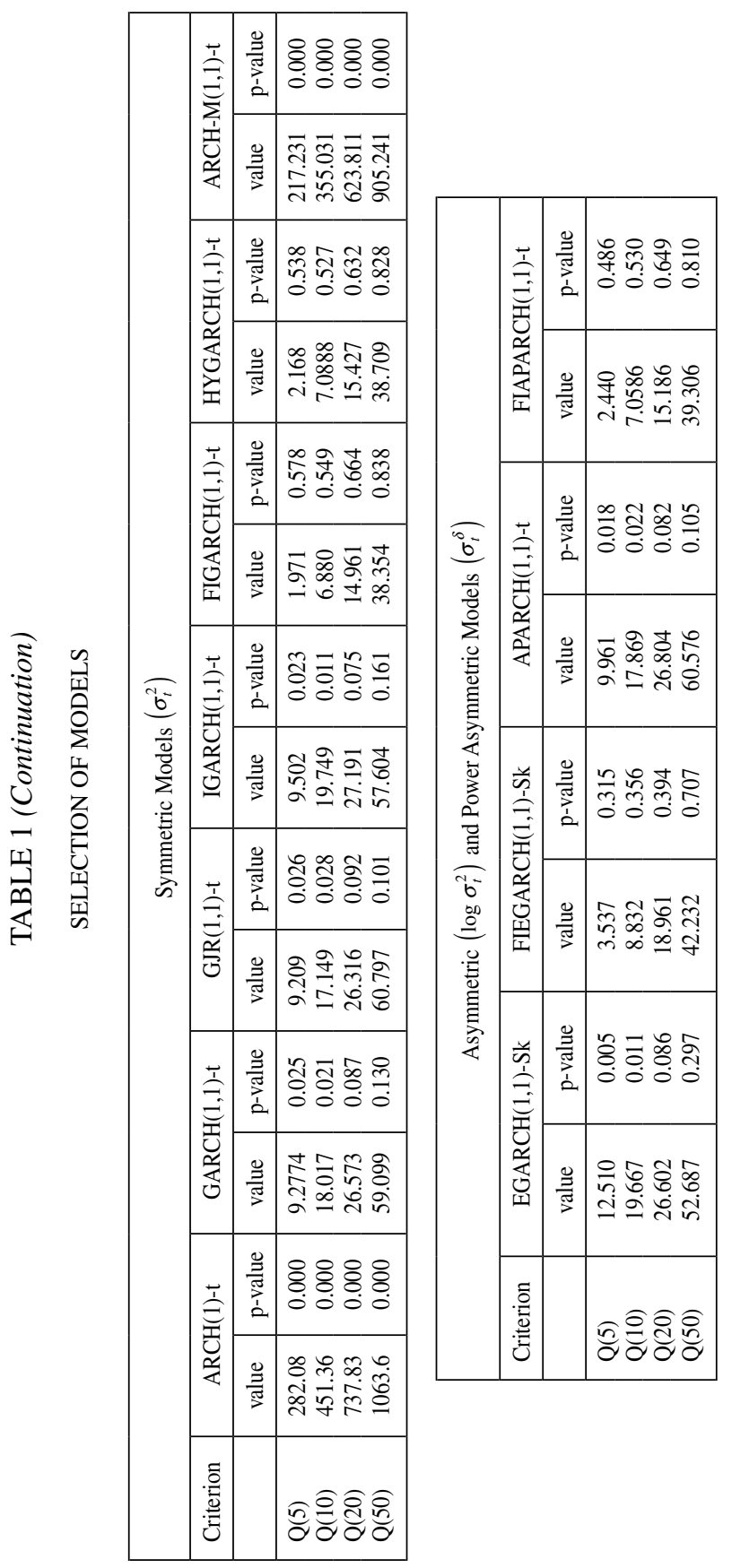




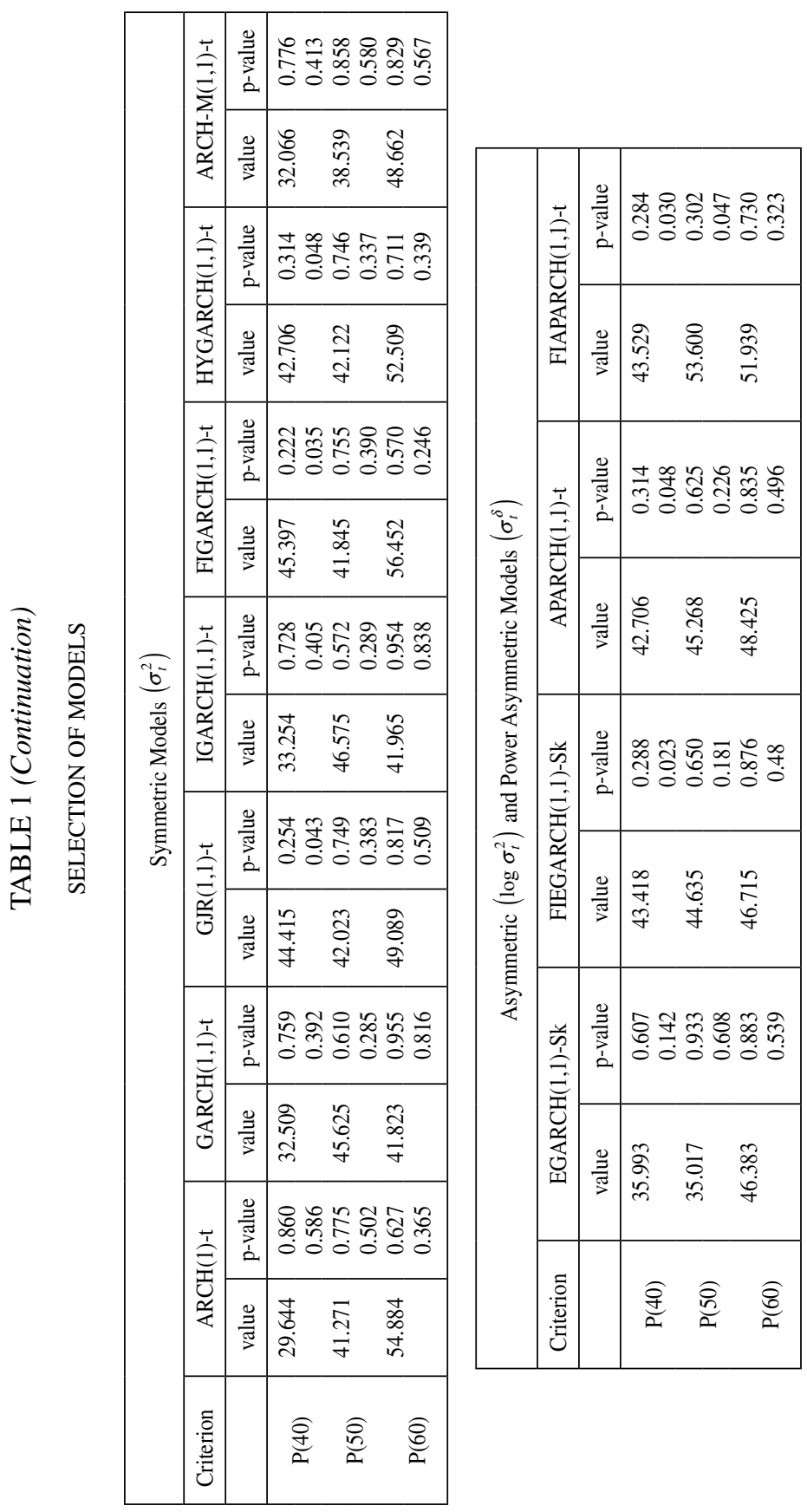

